\title{
Biocontrol program targets Asian citrus psyllid in California's urban areas
}

\author{
Two parasitoids of the Asian citrus psyllid, from Pakistan, have been released in Southern California \\ with promising results.
}

by Ivan Milosavljević, Kelsey Schall, Christina Hoddle, David Morgan and Mark Hoddle

A sian citrus psyllid (ACP), Diaphorina citri Kuwayama (Hemiptera: Liviidae), has emerged as the most important exotic insect pest of citrus in California. Damage is two-fold. First, psyllids cause direct injury to citrus through feeding on phloem juice in immature foliage, deforming the leaves (Halbert and Manjunath 2004); and second, and more importantly, they vector the bacterium Candidatus Liberibacter asiaticus (CLas), which causes the lethal and untreatable citrus disease, huanglongbing (HLB), also called citrus greening disease.

Characteristic symptoms associated with CLas infection are reduced vigor, foliar discoloration and dieback, misshapen fruit with bitter juice and malformed seeds, premature fruit drop, overall yield reductions and, ultimately, tree death (Gottwald 2010). Though symptoms may not appear for several years, CLasinfected plants are bacteria reservoirs from which ACP acquires and spreads the HLB-causing pathogen. CLas spread is exacerbated prior to detection if ACP populations are high and not managed. While there are some differences in susceptibility across citrus varieties, virtually all commercially available varieties are vulnerable to CLas infection.

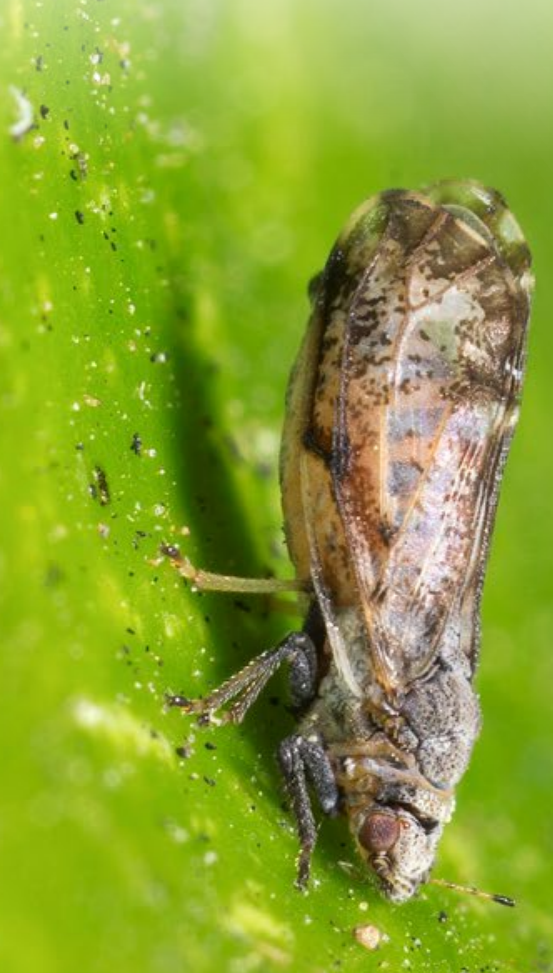

\section{Abstract}

In California, Asian citrus psyllid vectors the bacterium Candidatus Liberibacter asiaticus, which causes the lethal citrus disease huanglongbing. The top priority for California's citrus industry has been to diminish the rate of bacterium spread by reducing Asian citrus psyllid populations in urban areas, where this pest primarily resides. Attempts at eradicating and containing the psyllid with insecticides were unsuccessful. An alternative approach has been a classical biological control program using two parasitoids from Pakistan, Tamarixia radiata and Diaphorencyrtus aligarhensis, which attack the psyllid nymphs. T. radiata has established widely and, in combination with generalist predators, natural enemies are providing substantial control of psyllids in urban areas.

HLB is the most important vector-borne disease threat to the citrus industry in the United States. ACP and CLas were first found in the United States in Florida in 1998 and 2005, respectively (GraftonCardwell et al. 2013). Since then, the ACP-CLas pathosystem has been detected in six U.S. states, and ACP establishment has been confirmed in 10 U.S. states.

The emergence of HLB in Florida citrus orchards has had significant economic impacts. Approximately $75 \%$ of all citrus trees grown in Florida are infected with CLas. Consequently, production costs have increased by $33 \%$ because of increased ACP-CLas management, and productive acreage has declined by $44 \%$ (from a high of 815,100 acres in
Online: https://doi.org/10.3733/ ca.2017a0027

Asian citrus psyllids spread huanglongbing, a lethal citrus disease that poses a serious threat to the U.S. citrus industry. Psyllid populations are now established in urban areas of Southern California, where a classical biological control program with parasitoids from Pakistan is attempting to reduce psyllid numbers and migration into commercial citrus production areas. 

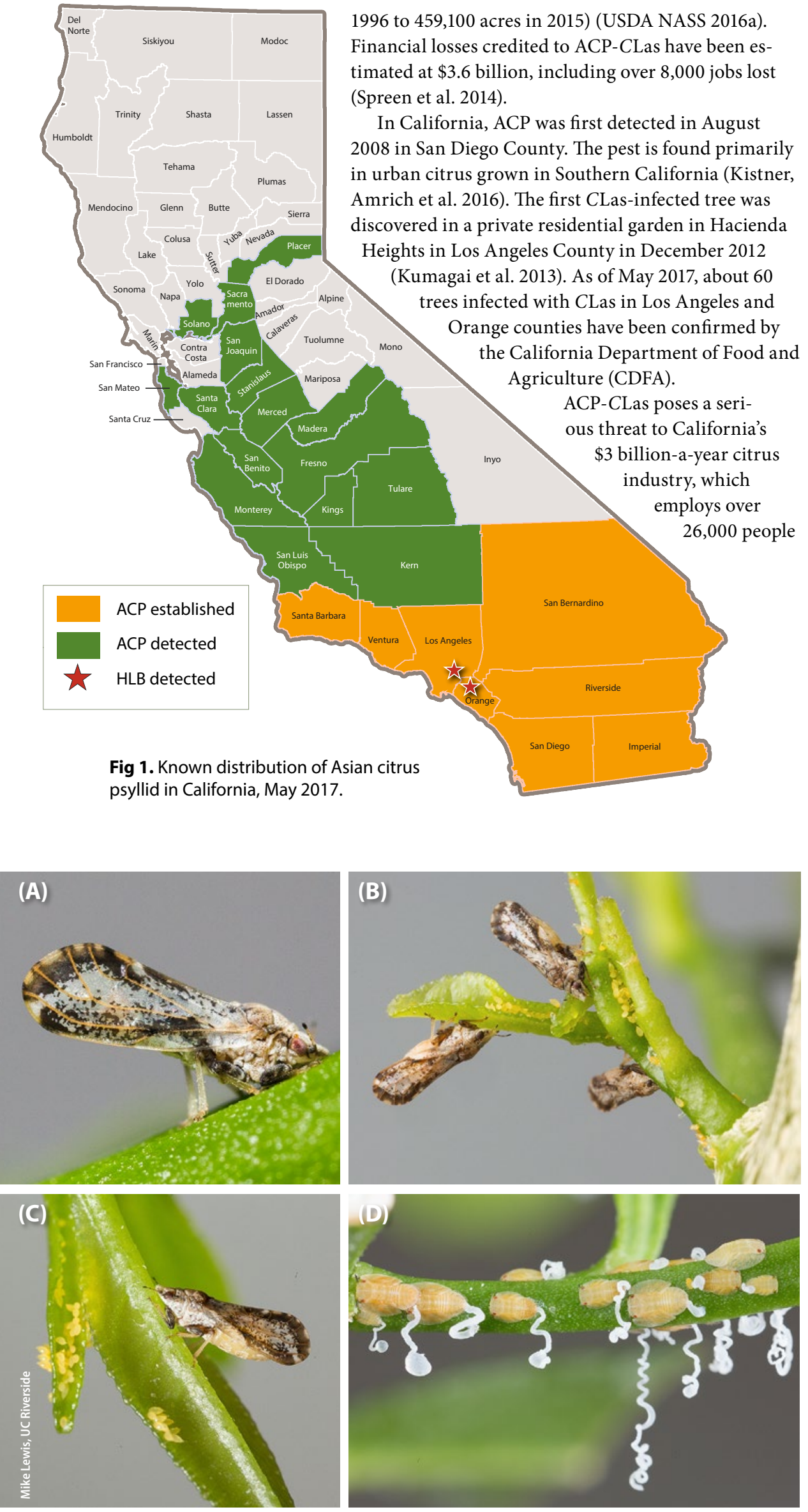

(Richards et al. 2014). California is the number one producer of fresh-market citrus in the United States, supplying more than $85 \%$ of the oranges, mandarins and tangerines and over $90 \%$ of the lemons (USDA NASS 2016b). There is zero industry tolerance for misshapen and bitter fruit in California's fresh-market citrus crop. California growers are already faced with escalating ACP-HLB management costs, and economic forecasts indicate that expenses associated with ACP$C$ Las may rise to $\$ 220$ million a year in the next 5 years (Bennet 2016).

CLas spreads rapidly through ACP populations and citrus groves (Hall et al. 2013). Citrus orchards may become economically unfeasible 2 to 5 years following infection of the first tree (Bassanezi and Bassanezi 2008). The most important contributing factors to rapid spread of CLas by ACP are (A) the high dispersal potential of adult psyllids, which is facilitated by their good flight capabilities and small size, enabling them to be blown long distances by wind and go undetected on shipped plants and (B) rapid psyllid population growth, which results from short generation times and the high fecundity of females (Lewis-Rosenblum et al. 2015). Additionally, uninfected psyllids are more attracted to CLas-infected trees than to uninfected trees, which may further facilitate rapid pathogen spread (Mann et al. 2012). Thus, suppressing ACP populations is important for reducing CLas movement, which in turn maximizes orchard longevity and productivity.

\section{Growing concerns about ACP}

As of 2017, ACP populations have been found in 24 counties throughout California (CDFA 2017a), including the major commercial citrus production area in the San Joaquin Valley, which accounts for $\sim 77 \%$ of California's citrus industry (fig. 1) (USDA NASS 2016b). Fortunately, the commercial production areas have not yet suffered from the widespread establishment of the ACP-CLas complex. The distribution of CLas has remained largely restricted to Hacienda Heights, San Gabriel and Cerritos in Los Angeles County and Anaheim in Orange County (fig. 1).

A heat risk map for HLB in Southern California has been developed by the U.S. Department of Agriculture (USDA), and this probabilistic map is used to direct ACP natural enemy releases (see below for details on ACP parasitoids imported from Pakistan) in urban areas in accordance with perceived likelihood of the occurrence of CLas-infected trees (fig. 2A). As ACP continues to spread, there is an increased risk of ACPCLas establishing in major citrus growing areas of California.

Asian citrus psyllid life stages: (A) adult psyllid feeding on young tissue, $(B, C)$ gravid adult females and eggs on citrus flush and (D) nymphs producing white honeydew secretions that are harvested by Argentine ants. 
In an attempt to eradicate ACP populations in residential areas, the CDFA ran pesticide application and monitoring programs during the initial stages of the ACP invasion into Southern California (Hoddle 2012). Pesticide applications consisted of fast-acting cyfluthrin foliar sprays followed with slower-acting and persistent systemic imidacloprid soil drenches. While the CDFA spray program was moderately successful in killing ACP on infested backyard citrus, it was prohibitively expensive, at $\sim \$ 200$ million (approximately $\$ 100$ per property), and it was estimated that less than $10 \%$ of residential citrus at risk of ACP infestation was treated. Consequently, the ACP urban spray program was largely terminated in 2012 after 3 years (Hoddle and Pandey 2014).

Following the first detection in San Diego County, ACP rapidly spread throughout Southern California. Established populations also have now been recorded in the Central Coast (2009), Central Valley (2012) and the greater San Francisco Bay Area (2014) (fig. 1). In response to this spread, a CDFA-appointed ACP quarantine first implemented in September 2008 in San Diego was initially restricted to 20 square miles (52 square kilometers) (Victoria Hornbaker, CDFA, personal communication); it has now increased and spans 24 counties encompassing over 62,000 square miles (160,000 square kilometers) (CDFA 2017a). The quarantine aims to reduce ACP-CLas spread by regulating the movement of citrus and closely related species (CDFA 2017b).

Backyard citrus represents a large portion of total citrus acreage in California. In Los Angeles County alone, it has been estimated that over 1.2 million residences may have at least one backyard citrus plant (Hoddle 2012). Residential areas are important reservoirs for ACP and CLas in California, and there is a high risk of infected vectors moving from these areas into commercial groves (Gottwald 2010).

In Florida, abandoned citrus groves have been identified as significant reservoirs for ACP and CLas, with infected psyllids dispersing to commercial groves in spring and summer (Lewis-Rosenblum et al. 2015). Most commercial citrus production areas in California are naturally arid, so abandoned groves tend not to persist; however, abandoned citrus in moister coastal areas could become reservoirs. Neglected citrus groves may become more common across the state if CLas becomes more widely established and increased management costs make production unprofitable.

Native rutaceous plants (i.e., citrus relatives) are widely distributed in California wilderness areas, especially in strategically significant locations near commercial production areas in the San Joaquin and Coachella valleys and Imperial and San Diego counties (Calflora 2017). It is unknown if these wilderness areas harbor ACP-CLas populations or if they could act as potential spillover hot spots for ACP-CLas spread, as migrating ACP could introduce CLas into commercial citrus production areas (Grafton-Cardwell et al. 2013).
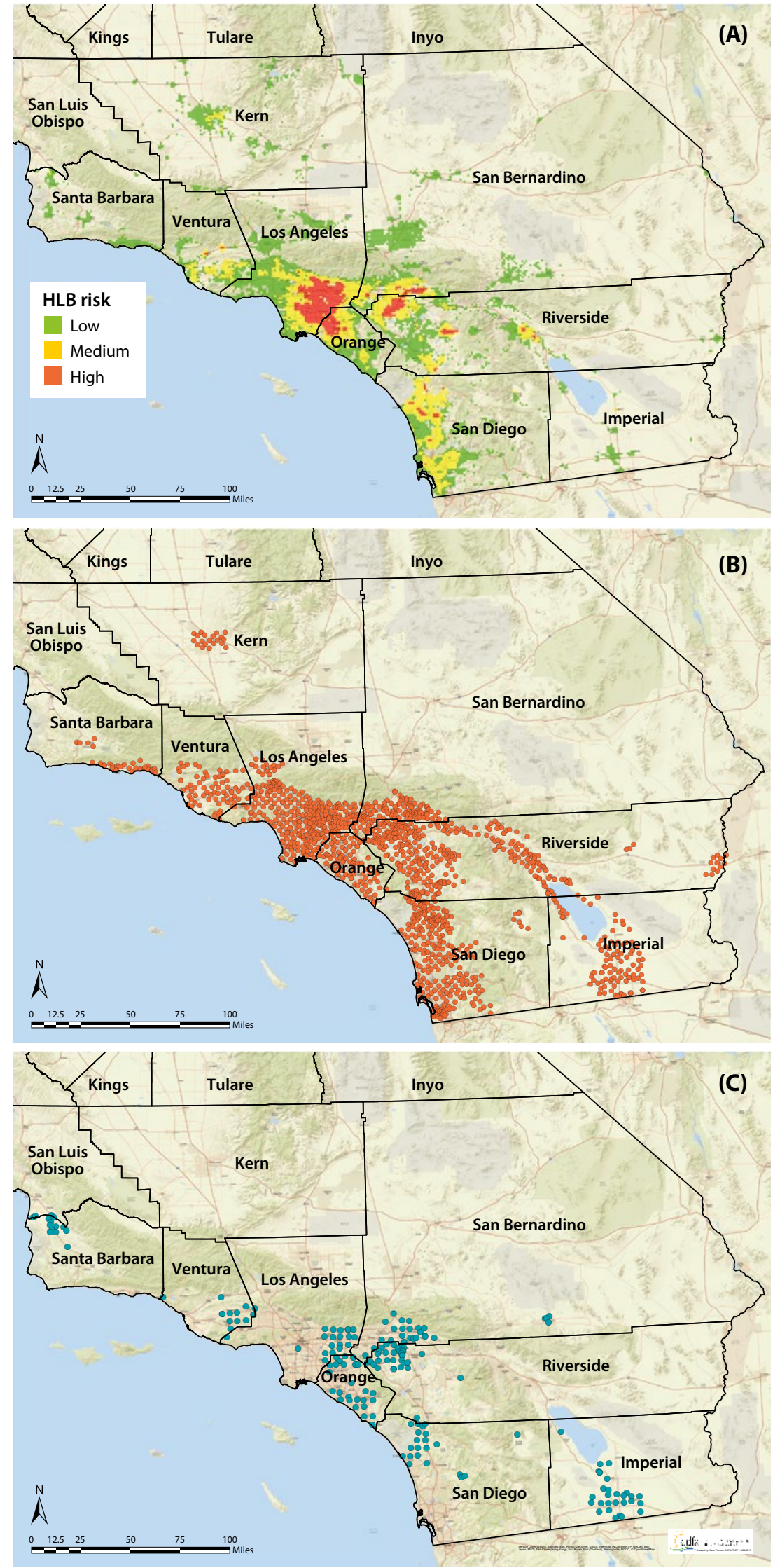

Fig. 2. (A) Huanglongbing risk grids generated by USDA researchers in 2016. Southern California release locations through 2016 of the psyllid parasitoids (B) Tamarixia radiata and (C) Diaphorencyrtus aligarhensis. 
Huanglongbing symptoms, photographed in Florida: (A) irregular blotchy yellowing or mottling of leaves and (B) reduced plant vigor and foliar dieback in CLas-infected citrus trees in advanced stages of decline.

Researchers estimate that the Florida citrus industry has lost $\$ 3.6$ billion, including over 8,000 jobs, as a result of HLB (Spreen et al. 2014).
In the absence of insecticide management, biological control of ACP may be the only feasible population suppression tool in areas (i.e., urban environments, wilderness areas, and organic or abandoned citrus orchards) not under active management.

\section{Natural enemy prospecting program}

Initial surveys of ACP populations in urban-grown citrus, and the subsequent rearing and dissection of recovered nymphs, revealed a lack of specialist natural enemies (e.g., parasitoids), which may be the reason ACP populations spread rapidly in Southern California (Hoddle 2004, 2012). This apparent lack of specialist natural enemies, coupled with the cessation of CDFA's urban spray programs for ACP control, prompted a search for effective biological control agents to suppress ACP population growth.

Beginning in September 2010, researchers at UC Riverside in collaboration with CDFA and USDA scientists initiated development of a classical biological control program targeting ACP populations in urban Southern California. Diaphorina citri has a native range that includes the Indian subcontinent (Beattie et al. 2009). Natural enemy prospecting was conducted in the Punjab province of Pakistan, because climate matching indicated that this area has a $\sim 70 \%$ climate match with the major citrus production areas in California's Central Valley (Hoddle and Pandey 2014). Biocontrol theory suggests that climate matching is important for improving the likelihood that a natural enemy will establish in the intended introduced range; preadaptation to the prevailing climate eases at least one establishment barrier (Van Driesche et al. 2008).
Hussain and Nath (1927) stated in their treatise on D. citri that the diversity of parasitoid species associated with ACP nymphs in Punjab was high, with possibly nine species being recorded attacking immature stages. Their work, however, resulted in the description of just one parasitoid species, Tamarixia radiata (Waterston) (Hymenoptera: Eulophidae). The identities of the other species were not known when California's ACP biocontrol program commenced.

Foreign exploration efforts by UC Riverside scientists in Punjab were conducted in collaboration with researchers in the Department of Entomology at the University of Agriculture, Faisalabad. This excellent cooperative arrangement was essential for the successful collection of ACP natural enemies from citrus production areas around Sargodha, Toba Tek Singh, Faisalabad and Gujranwala.

\section{Safeguards to minimize risks}

Potential natural enemy species from Punjab, Pakistan, were imported under a USDA APHIS permit into quarantine at UC Riverside from April 2011 to April 2013. These collections resulted in the rearing of 3,675 parasitoids from which $13 \mathrm{ACP}$-associated parasitoid species were identified (Hoddle et al. 2014). Two species were particularly highly represented: $55 \%$ of collected parasitoids were identified as $T$. radiata and $28 \%$ were Diaphorencyrtus aligarhensis (Shafee, Alam and Argarwal) (Hymenoptera: Encyrtidae) (Hoddle 2012).

The 11 other parasitoid species included three leaf miner parasitoids, two egg parasitoids, one scale parasitoid and five obligate hyperparasitoids of $T$. radiata and D. aligarhensis; these additional 11 parasitoid species do not attack ACP (Bistline-East and Hoddle 2014,
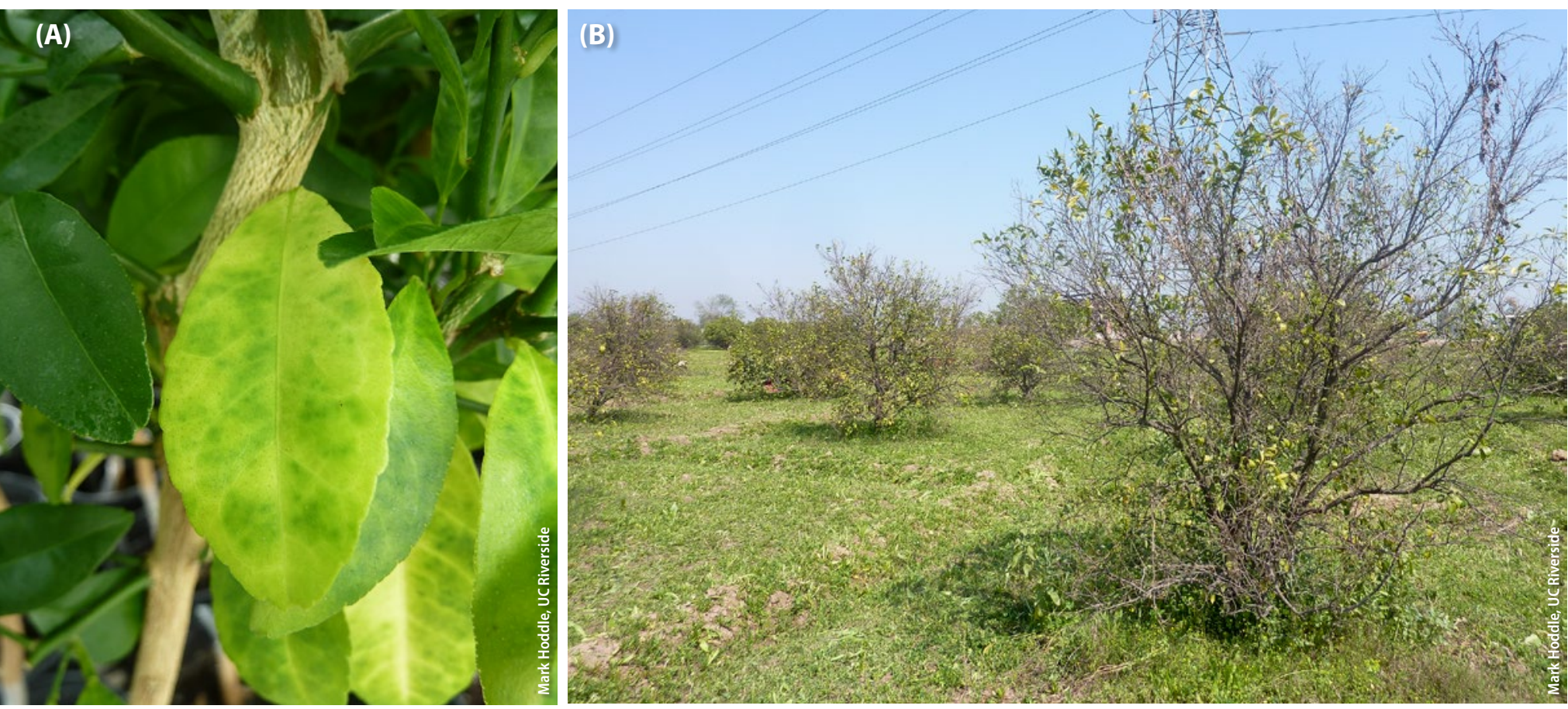

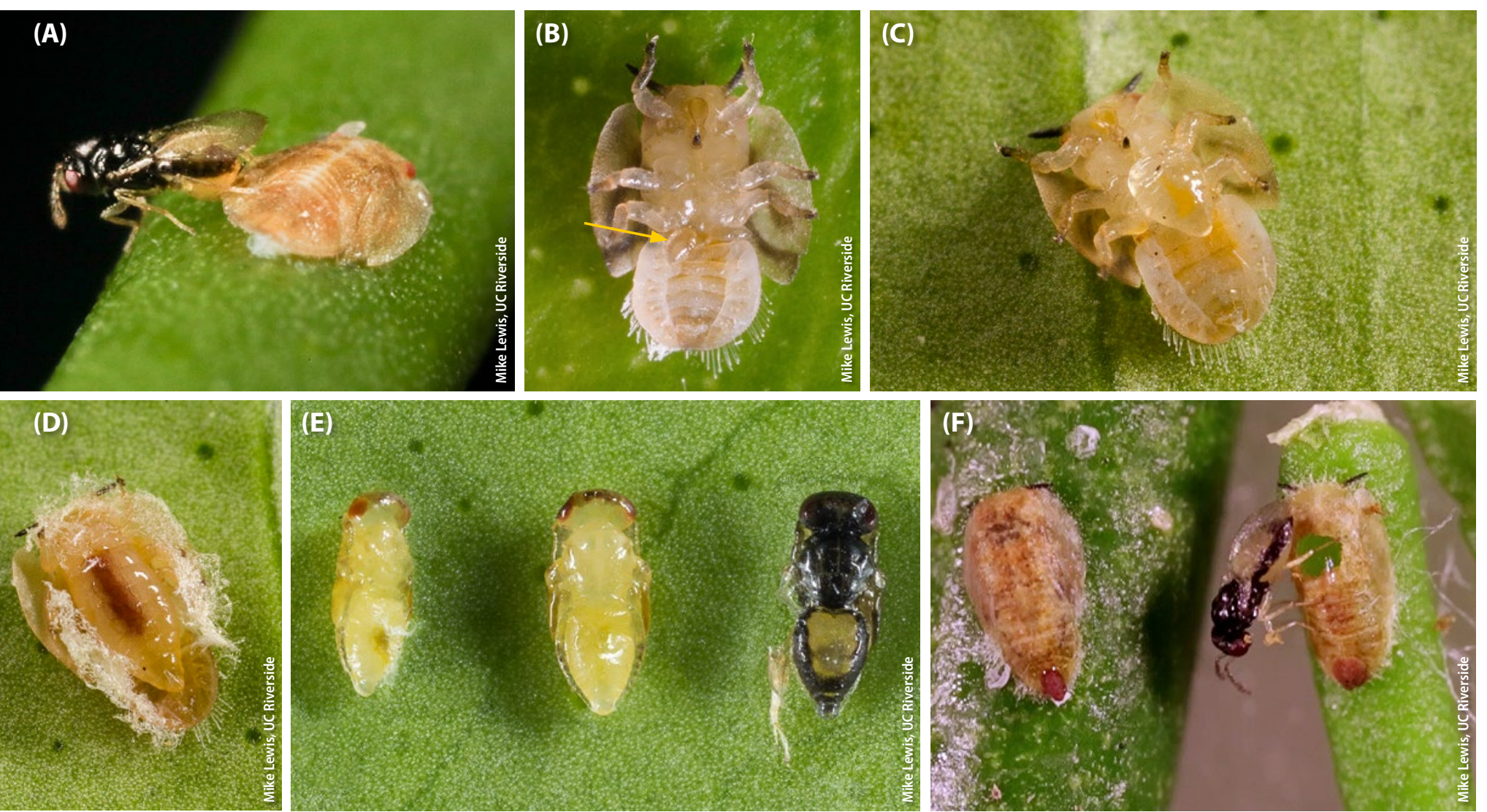

Tamarixia radiata developmental biology: (A) female laying an egg underneath a psyllid nymph, (B) parasitoid egg (arrow) attached to its host, (C, D) T. radiata nymph feeding externally on its host, (E) developing T. radiata pupae removed from ACP mummies and (F) an adult T. radiata that has emerged from the anterior region (circular exit hole) of the ACP mummy. T. radiata has established widely in Southern California since releases began in late 2011 .

Adult Diaphorencyrtus aligarhensis (A) male and (B) female. Because $D$. aligarhensis parasitizes different ACP life stages than $T$. radiata, researchers are exploring the idea that the two species, which coexist in their native range, could complement each other in their attacks on ACP.

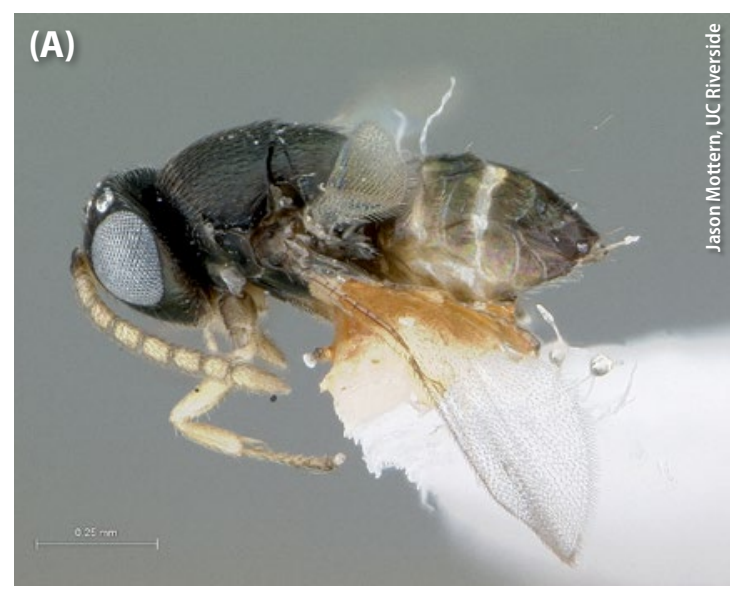

in Florida are varied and may include the parasitoid's high sensitivity to pesticide residues in commercial citrus groves, low levels of genetic variation in released parasitoids that may have reduced their fitness and subsequent efficacy, and interference by ants tending honeydew-producing ACP nymphs (Navarrete et al. 2013). Studies in Florida have shown coccinellid predation of ACP nymphs already parasitized by $T$. radiata can result in over $95 \%$ mortality of developing T. radiata. This is an additional factor potentially contributing to low parasitism rates observed in Florida (Qureshi and Stansly 2009).

The second natural enemy species that has been released in California is D. aligarhensis, a host-specific solitary endoparasitoid of second through fourth instar ACP nymphs (Bistline-East et al. 2015). Like T. radiata, D. aligarhensis kills its hosts through a combination of parasitism and host feeding, and a single D. aligarhensis female can kill up to 280 nymphs in her lifetime (Rohrig et al. 2011). Releases of D. aligarhensis began in California in December 2014 (Vankosky and Hoddle 2016). By February 2017, over 300,000 D. aligarhensis had been released in urban Southern California by CDFA and UC Riverside (fig. 2C).

The concept underly-

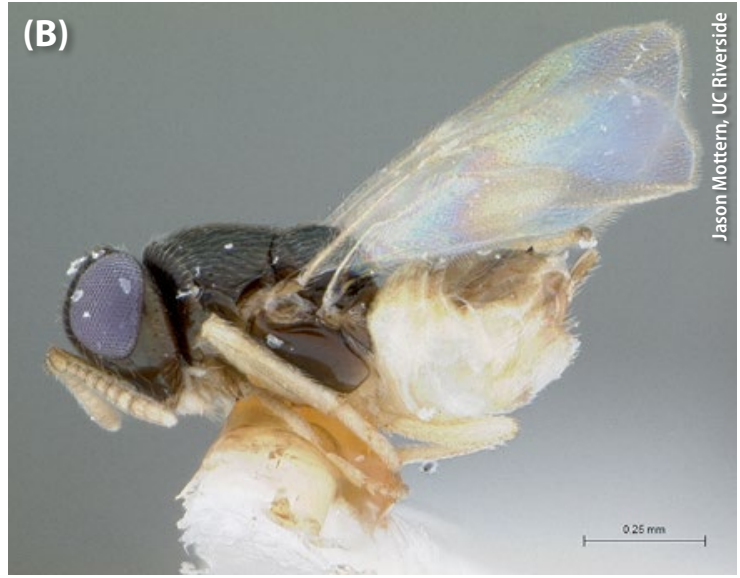
ing efforts to establish two ACP parasitoid species in California is that $D$. aligarhensis may complement $T$. radiata because the two parasitoids have preferences for different ACP life stages and both species coexist in their native range and contribute to ACP control in citrus (Khan et al. 2014). While it is uncertain at this stage as to whether 

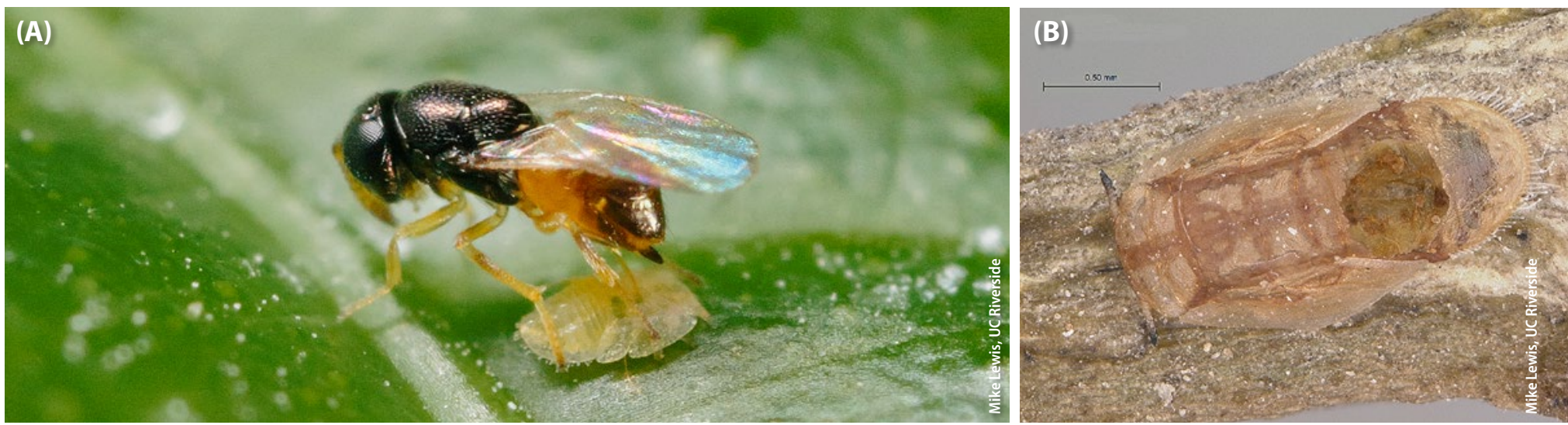

The developmental biology of Diaphorencyrtus aligarhensis: (A) gravid female lays an egg inside the psyllid nymph; (B) in contrast to T. radiata, an adult $D$. aligarhensis emerges from the posterior of the ACP mummy. Studies of $D$. aligarhensis releases have not been completed yet, but early results indicate the species is able to reproduce in California urban citrus.

or not $T$. radiata and D. aligarhensis will be complementary in their attacks on ACP, several other biocontrol programs targeting invasive pests of citrus in California have been successful because of established natural enemy complexes. The most notable are cottony cushion scale, Icerya purchasi (Maskell) (Hemiptera: Monophlebidae), suppression by the coccinellid Rodolia cardinalis Mulsant in hot desert areas, and the parasitic fly Cryptochaetum iceryae (Williston) (Diptera: Cryptochaetidae) in cooler coastal zones (Quezada and DeBach 1973).

Releases of $D$. aligarhensis failed to establish populations in Florida. As seen previously with T. radiata, several factors may have led to this failure: (1) intensive insecticide use in citrus growing areas where $D$. aligarhensis was released (Rohrig et al. 2012), (2) the inferior competitiveness of $D$. aligarhensis compared to the widely established populations of $T$. radiata (Rohrig et al. 2012) and (3) the relatively low D. aligarhensis release numbers and frequency, which may not have been adequate to overcome establishment barriers.

Release and impact studies are still in progress, so it is too early to conclude that D. aligarhensis has established in California. However, evidence of D. aligarhensis parasitism of ACP has been found at over $85 \%$ of sites where this species was released. This finding tentatively suggests that $D$. aligarhensis can find ACP nymphs and is able to reproduce in California urban citrus, and that it may be able to coexist with $T$. radiata in this environment. Collectively, the two parasitoid species may intensify biocontrol of ACP in areas where they operate sympatrically.

\section{Impacts of generalist natural enemies and invasive ants}

California's biological control program targeting ACP has focused primarily on monitoring parasitoid establishment and their rates of spread and measuring levels of parasitoid-related mortality. However, a suite of naturally occurring generalist predators have been identified as important contributors to ACP mortality in urban areas. Studies conducted in Southern California have identified larvae of syrphid flies (Diptera: Syrphidae) and lacewings (Neuroptera: Chrysopidae) as members of this important predator guild (Kistner, Melhem et al. 2016). Field studies indicate that syrphid and lacewing larvae may account for $~ 86 \%$ of ACP predation events, and mortality rates for experimental cohorts of ACP nymphs may reach 93\% (Kistner, Melhem et al. 2016).

Exchanges between natural enemies and ants that disrupt natural enemy activity are highly relevant interactions affecting biocontrol success. Ants are widely recognized as natural enemy antagonists because of the food-for-protection mutualisms they form with honeydew-producing hemipterans (HPHs), like ACP. Many species of HPH are invasive, economically damaging pests (e.g., aphids, mealybugs, scales, whiteflies and psyllids) (Helms 2013).

In addition to directly protecting HPHs from natural enemies, ants disperse tended pests to new foraging areas and provide sanitation services to HPHs, which

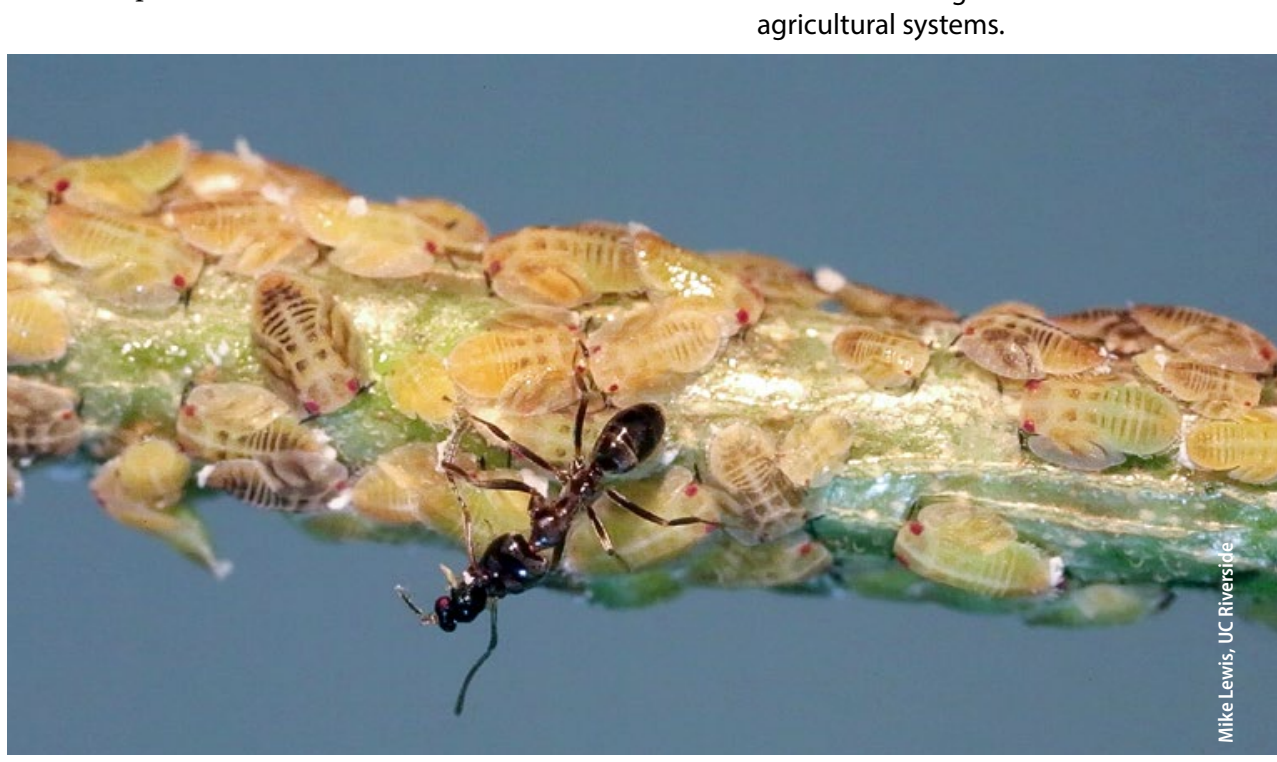

An Argentine ant captures a foraging adult $T$. radiata. Argentine ants tend colonies of ACP nymphs for the collection of honeydew. Worker ants protect the nymphs from natural enemies, which can significantly reduce biological control of ACP. Research suggests that liquid poison baiting is an effective tool in reducing ant infestations in citrus and other managed agricultural systems. 
reduce the incidence of disease and honeydew drowning. Furthermore, tended HPHs may respond to ant presence by increasing their rate of phloem ingestion, resulting in more rapid development and higher reproductive output (Yoo and Holway 2011). Because ants may exacerbate existing pest problems, ant control is a critical component of integrated pest management (IPM) programs targeting HPH pests, particularly programs that rely on biological control agents for population suppression. food resources. In groves with heavy HPH infestations, a citrus tree may receive more than a million L. humile visits in a day (K. Schall and M. Hoddle, unpublished data). In a survey of urban citrus gardens in Southern California, L. humile was present in $\sim 90 \%$ of surveyed trees, with $\sim 55 \%$ of ACP colonies tended by workers. At these sites, ACP parasitism by T. radiata was significantly higher in citrus lacking L. humile (>90\%) than in citrus where L. humile was tending ACP colonies $(<12 \%)$ (Tena et al. 2013).

\section{It is anticipated that biological control of ACP in California will increase the efficacy and sustainability of other control strategies, including insecticide-reliant programs, because lower populations of ACP may need less management, and less frequent insecticide applications will slow the development of pesticide resistance.}

The results of replicated field trials in urban citrus groves in Riverside, California, further clarified the implications of the $L$. humile-ACP relationship for ACP biocontrol. ACP parasitism by $T$. radiata was $70 \%$ to $800 \%$ higher and generalist predators were $\sim 1$ to 4

Given the considerable biocontrol efforts targeting ACP, there is a lack of research investigating the impact of ant-ACP mutualisms on natural enemy efficacy. Although studies from Florida found that ACP parasitism by T. radiata was substantially higher in groves where ACP-tending ant species were controlled (Navarrete et al. 2013), this interaction remains largely unstudied with ant species in California.

In Southern California, the most ubiquitous ant found in citrus is the invasive Argentine ant, Linepithema humile (Mayr) (Hymenoptera: Formicidae). This notoriously pestiferous and ecologically disruptive species has thrived in California for over a century. L. humile infestations are most extensive within managed environments, such as the citrus agroecosystem, because of irrigation and abundant

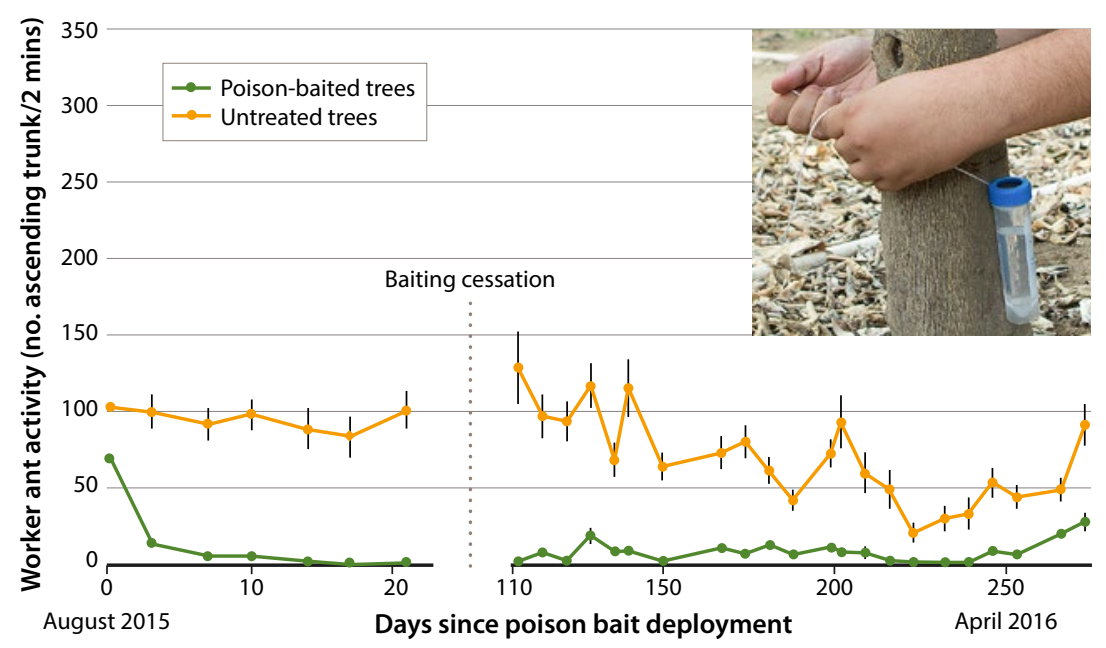

Fig. 3. Visual two-minute assessments of Argentine ant activity on 33 liquid poisonbaited $(0.0001 \%$ thiamethoxam in a $25 \%$ sucrose solution) and untreated navel orange trees in an unsprayed citrus grove over a 9-month period. Activity on baited trees decreased by $\sim 75 \%$ within a few days of treatment and remained near 0 for the entire baiting period. Following bait removal in November, activity on previously baited trees was low and did not show signs of recovery until late April. times more abundant in ACP colonies where L. humile was excluded or controlled, using a sticky barrier or liquid poison bait, compared to unmanaged populations of ants that had access to ACP nymphs (Schall and Hoddle 2017).

The high frequency of antagonistic interactions observed between L. humile and natural enemies of ACP is likely responsible for the disparities observed between treatments. For example, conflict with ants on citrus flush often resulted in prematurely terminated oviposition attempts by T. radiata, allowing ACP nymphs to escape parasitism. In some instances, ants were observed to capture and kill foraging T. radiata.

Together, these results suggest that $L$. humile can significantly suppress ACP biocontrol. Implementation of a liquid baiting regime for L. humile management is a highly effective method for improving biocontrol and reducing infestations of ant-tended $\mathrm{HPH}$ pests in managed agricultural systems (Cooper et al. 2008), including citrus (fig. 3) (Schall and Hoddle 2017).

\section{Future developments}

It is anticipated that biological control of ACP in California will increase the efficacy and sustainability of other control strategies, including insecticide-reliant programs, because lower populations of ACP may need less management, and less frequent insecticide applications will slow the development of pesticide resistance. Reduced ACP populations resulting from natural enemy activity may also suppress rates of $C$ Las spread and reduce economic losses resulting from HLB development in orchards.

However, ACP population suppression by natural enemies alone is unlikely to provide complete suppression of CLas spread in California. To reduce rates of CLas spread further, especially in commercial citrus production areas, IPM programs targeting ACP need to be developed that successfully incorporate a suite 
of complementary population control tools including natural enemies, ant suppression, insecticides and possibly the development of new citrus varieties tolerant of or resistant to ACP-CLas. Because ACP is significant within a complex of citrus pests, incipient management programs will need to be accommodating of well-developed control practices for other key citrus pests (e.g., California red scale) to minimize disruption of those existing programs. CA
I. Milosavljević is Postdoctoral Researcher, K.A. Schall is Ph.D. Candidate and C.D. Hoddle is Assistant Specialist in the Department of Entomology, UC Riverside; D.J.W. Morgan is Environmental Program Manager in the California Department of Food and Agriculture, Mount Rubidoux Field Station, Riverside; and M.S. Hoddle is UC Cooperative Extension Specialist in Biological Control in the Department of Entomology and Director of the Center for Invasive Species Research, UC Riverside.

\section{References}

Bassanezi RB, Bassanezi RC. 2008. An approach to model the impact of huanglongbing on citrus yield. In: Gottwald TR, Graham JH (eds.). Proc Int Res Conf Huanglongbing, Dec. 1-5, 2008. Orlando, FL. p 301-4.

Beattie GAC, Holford P, Haigh AM, Broadbent P. 2009. On the origins of Citrus, Huanglong bing, Diaphorina citri and Trioza erytreae. In: Gottwald TR, Graham JH (eds.). Proc Int Res Conf Huanglongbing, Dec. 1-5, 2008 Orlando, FL. p 23-56. www. plantmanagementnetwork.org/ proceedings/irchlb/2008/.

Bennet R. 2016. Our \#1 goal: Controlling HLB. The ultimate and only objective. Citrograph 7:8-10.

Bistline-East A, Hoddle MS. 2014. Chartocerus sp. (Hymenoptera: Signiphoridae) and Pachyneuron crassiculme (Hymenoptera: Pteromalidae) are obligate hyperparasitoids of Diaphorencyrtus aligarhensis (Hymenoptera: Encyrtidae) and possibly Tamarixia radiata (Hymenoptera: Eulophidae). Fla Entomol 97:562-6.

Bistline-East A, Hoddle MS. 2016. Biology of Psyllaphycus diaphorinae (Hymenoptera: Encyrtidae), a hyperparasitoid of Diaphorencyrtus aligarhensis (Hymenoptera: Encyrtidae) and Tamarixia radiata (Hymenoptera: Eulophidae). Ann Entomol Soc Am 109:22-8.

Bistline-East A, Pandey R, Kececi $M$, Hoddle MS. 2015. Host range testing of Diaphorencyrtus aligarhensis (Hymenoptera: Encyrtidae) for use in classical biological control of Diaphorina citri (Hemiptera: Liviidae) in California. J Econ Entomo 108:940-50.

Calflora. 2017. California Flora Database. Berkeley, CA. http:// calflora.org/ (accessed Feb. 28, 2017).

[CDFA] California Department of Food and Agriculture. 2017a. CDFA ACP/HLB Regulation and Quarantine Boundaries. www.cdfa.ca.gov/plant/acp/ regulation.html (accessed Feb. 28, 2017).
CDFA 2017b. ACP Partial Host List. www.cdfa.ca.gov/ plant/acp/docs/factsheets/ ACP HOST_LIST_partial.pdf (accessed Feb. 28, 2017).

Chien CC, Chu YI, Ku SC. 1995 Influences of host densities on the population increase of the eulophid wasp, Tamarixia radiata, and its host-killing ability. Plant Prot Bull Taipei 37:81-96. Cooper M, Daane K, Nelson E, et al. 2008. Liquid baits control Argentine ants sustainably in coastal vineyards. Calif Agr 62:177-83.

Gottwald TR. 2010. Current epidemiological understanding of citrus huanglongbing. Annu Rev Phytopathol 48:119-39.

Grafton-Cardwell EE, Stelinski LL, Stansly PA. 2013. Biology and management of Asian citrus psyllid, vector of the huanglongbing pathogens. Annu Rev Entomol 58:413-32.

Halbert SE, Manjunath KL. 2004. Asian citrus psyllids (Sternorrhyncha: Psyllidae) and greening disease of citrus: A literature review and assessment of risk in Florida. Fla Entomol 87:330-53. Hall DG, Nguyen R. 2010. Toxicity of pesticides to Tamarixia radiata, a parasitoid of the Asian citrus psyllid. BioControl 55:601-11.

Hall DG, Richardson ML, Ammar ED, Halbert SE. 2013. Asian citrus psyllid, Diaphorina citri, vector of citrus huanglongbing disease. Entomol Exp Appl 146:207-23.

Helms KR. 2013. Mutualisms between ants (Hymenoptera: Formicidae) and honeydewproducing insects: Are they important in ant invasions? Myrmecological News 18:61-71. Hoddle MS. 2004. Restoring balance: Using exotic species to control invasive exotic species. Conserv Biol 18:38-49.

Hoddle MS. 2012. Foreign exploration for natural enemies of Asian citrus psyllid, Diaphorina citri (Hemiptera: Psyllidae), in the Punjab of Pakistan for use in a classical biological control program in California, USA. Pak Entomol 34:1-5.
Hoddle MS, Amrich R, Hoddle CD, Kistner EJ. 2016. Where's Tamarixia? Citrograph 7:64:66.

Hoddle MS, Hoddle CD, Triapitsyn SV, et al. 2014. How many primary parasitoid species attack nymphs of Diaphorina citri (Hemiptera: Liviidae) in Punjab, Pakistan? Fla Entomo 97:1825-8.

Hoddle MS, Pandey R. 2014 Host range testing of Tamarixia radiata (Hymenoptera:

Eulophidae) sourced from the Punjab of Pakistan for classica biological control of Diaphorina citri (Hemiptera: Liviidae: Euphyllurinae: Diaphorinini) in California. J Econ Entomol 107:125-36

Hoy MA, Nguyen R. 2001. Classical biological control of Asian citrus psylla. Citrus Ind 81:48-50.

Hussain MA, Nath D. 1927. The citrus psylla (Diaphorina citri Kuw.) (Psyllidae: Homoptera). Indian Department of Agriculture Memoirs Entomological Series, vol. 10. Government of India Central Publication Branch. p 5-27.

Khan SZ, Arif MJ, Hoddle CD, Hoddle MS. 2014. Phenology of Asian citrus psyllid (Hemiptera: Liviidae) and associated parasitoids on two species of Citrus, kinnow mandarin and sweet orange, in Punjab Pakistan. Environ Entomol 43:1145-56.

Kistner EJ, Amrich R, Castillo M et al. 2016. Phenology of Asian citrus psyllid (Hemiptera: Liviidae), with special reference to biological control by Tamarixia radiata, in the residential landscape of Southern California. J Econ Entomol 109(3):1047-57.

Kistner EJ, Melhem N, Carpente $E_{\text {, et al. 2016. Abiotic and biotic }}$ mortality factors affecting Asian citrus psyllid (Hemiptera: Livi-

dae) demographics in Southern California. Ann Entomol Soc Am 109(6):860-71.

Kumagai LB, LeVesque CS, Blomquist $\mathrm{CL}$, et al. 2013. First report of Candidatus Liberibacter asiaticus associated with citrus huanglongbing in California. Plant Dis 97:283.
Lewis-Rosenblum H, Martini X Tiwari S, Stelinski LL. 2015. Seasonal movement patterns and long-range dispersal of Asian citrus psyllid in Florida citrus. Econ Entomol 108:3-10.

Mann RS, Ali JG, Hermann SL, et al. 2012. Induced release of a plant-defense volatile 'deceptively' attracts insect vectors to plants infected with a bacterial pathogen. PLoS Pathog 8:e1002610.

Michaud JP. 2004. Natural mortality of Asian citrus psyllid (Homoptera: Psyllidae) in central Florida. Biol Control 29:260-9.

Navarrete B, McAuslane H, Deyrup M, Peña JE. 2013. Ants (Hymenoptera: Formicidae) associated with Diaphorina citri (Hemiptera: Liviidae) and their role in its biological control. Fla Entomol 96:590-7.

Quezada J, DeBach P. 1973. Bioecological and population studies of the cottony-cushion scale, Icerya purchasi Mask., and its natural enemies, Rodolia cardinalis Mul. and Cryptochaetum iceryae Will., in Southern California. Hilgardia 41(20):631-88.

Qureshi JA, Stansly P. 2009. Exclusion techniques reveal significant biotic mortality suffered by Asian citrus psyllid Diaphorina citri (Hemiptera: Psyllidae) populations in Florida citrus. Biol Control 50:129-36.

Richards TJ, Shanafelt DW Fenichel EP. 2014. Foreclosures and invasive insect spread: The case of Asian citrus psyllid. Am J Agric Econ 96:615-30.

Rohrig EA, Hall DG, Qureshi JA, Stansly PA. 2012. Field release in Florida of Diaphorencyrtus aligarhensis (Hymenoptera: Encyrtidae), an endoparasitoid of Diaphorina citri (Homoptera: Psyllidae), from mainland China. Fla Entomol 95:479-81.

Rohrig E, Shirk PD, Hall DG, Stansly PA. 2011. Larval development of Diaphorencyrtus aligarhensis (Hymenoptera: Encyrtidae), an endoparasitoid of Diaphorina citri (Hemiptera: Psyllidae). Ann Entomol Soc Am 104:50-8.

Schall KA, Hoddle MS. 2017. Disrupting the ultimate invasive pest partnership: How invasive ants impede biological control of ACP in southern California. Citrograph 8:38-43.

Spreen TH, Baldwin JP, Futch SH. 2014. An economic assessment of the impact of Huanglongbing on citrus tree plantings in Florida. J Hortic Sci 49:1052-5.

Tena A, Hoddle CD, Hoddle MS. 2013. Competition between honeydew producers in an ant-hemipteran interaction may enhance biological control of an invasive pest. Bull Entomol Res 103:714-23.

[USDA NASS] United States Department of Agriculture National Agricultural Statistics Services. 2016a. Citrus Production Forecast. www nass.usda. gov/Statistics_by_State/Florida/ Publications/Citrus/Citrus_Fore- 